\title{
El Consejo de Derechos Humanos de Naciones Unidas ¿Un avance en el desarrollo institucional de los derechos humanos?
}

\author{
The United Nations Council for Human Rights. \\ A step forward in the institutional development \\ of human rights?
}

Ma. Cecilia Añaños Meza*

\section{Resumen}

Dentro del marco de reformas del sistema de las Naciones Unidas, la Asamblea General creó el 15 de marzo de 2006 el Consejo de Derechos Humanos como sustituto de la Comisión de Derechos Humanos y estableció su marco normativo de actuación. Después de haber concluido en su primer año de trabajo las pautas básicas de su proceso constitutivo y empezando su segundo año dedicado propiamente a los temas de su mandato y a la puesta en marcha del nuevo mecanismo del Examen Periódico Universal, surgen críticas a su labor.

Este trabajo pretende ante todo dar luces sobre las verdaderas innovaciones que trae la creación del Consejo. Ello es posible dando una mirada a sus fines, funciones y estructura, teniendo como indicador a la Comisión. En un siguiente paso, nos ocuparemos de las críticas al Consejo, y para concluir se discernirá si su creación representa un

Profesora de integración, Paradigma Sprachendienst, Berlín (ceciliaan@web.de). Recibido el 7 de noviembre de 2007; aceptado el 23 de diciembre de 2007. 
avance en el desarrollo institucional de los derechos humanos dentro del sistema de las Naciones Unidas. Ello sin dejar de lado su importancia en la promoción de los derechos humanos a nivel global.

Palabras clave: Consejo de Derechos Humanos, Res. 60/251 de la Asamblea General, Comisión de Derechos Humanos,

\section{Abstract}

On March 15, 2006, within the framework of reforms of the United Nations System, the General Assembly established the Council on Human Rights; as a substitute for the Human Rights Commission and determined the General Assembly established its normative framework. After having concluded the basic guidelines of its constitutive process, during its first year and beginning of its second year devoted to the areas covered by its mandate as well as to starting to implement the new mechanism of Universal Periodic Review, some comments are due.

It is the purpose of this paper to attempt to shed light on the genuine innovations brought about, by the Council, including a look at its objects, role and structure, as well as to its relevance to the Commission. This paper will also address criticisms directed at the Council and ultimately determine whether such a body represents progress in the institutional development of human rights within the framework of the United Nations. This is without disregarding its importance for the promotion of human rights at a global level.

Key words: Human Rights Council, G. A. Res. 60/251, Commission on Human Rights, 
Ma. Cecilia AÑaños Meza • El Consejo de Derechos Humanos de Naciones Unidas...

\section{INTRODUCCIÓN}

El Consejo de Derechos Humanos ${ }^{1}$, nuevo órgano de las Naciones Unidas encargado de la protección universal de los derechos humanos, fue creado por resolución de la Asamblea General el 15 de marzo de 2006². Dicha resolución dispone al mismo tiempo la disolución de la Comisión de Derechos Humanos ${ }^{3}$ después de 59 años de existencia.

No nos detendremos a dilucidar los motivos que llevaron a la Asamblea General a tomar la decisión de disolver un órgano crucial para el mantenimiento de estandares internacionales en materia de derechos humanos y sustituirlo por otro, cuya estructura no se diferencia sustancialmente del anterior, como se verá más adelante. El Consejo de Derechos Humanos es un hecho, ha cumplido ya un año de existencia y está a puertas de empezar su segundo año de actividades con un programa de trabajo apretado, que incluye la puesta en marcha del nuevo mecanismo del Examen Periódico Universal.

Más que hacer un examen o evaluación provisional de las actuaciones del Consejo a poco más de un año de su

\footnotetext{
1 En adelante el Consejo «.

2 A/RES/60/251, accesible en español en: $<$ http://www.ohchr.org/spanish/bodies/hrcouncil/docs/A.RES.60.251._Sp.pdf >, visitado el 20 de agosto de 2007. Aprobada con 170 votos a favor, 4 en contra (Estados Unidos, Israel, Islas Marshall y Palau) y 3 abstenciones (Irán, Venezuela y Belarús).

3 En adelante «la Comisión».
}

creación ${ }^{4}$, centraremos la atención en la base política y legal en que descansa, haciendo las debidas comparaciones con su antecesora, la Comisión. Puesto que aparte de su nombre y creación muy poco de lo que existe en el Consejo es nuevo, se hace necesario repasar brevemente los logros y problemas de la Comisión.

En este trabajo procederemos a examinar al Consejo desde el punto de vista de sus fines, funciones y estructura, a fin de identificar y situar sus puntos fuertes y débiles y ver si representa realmente un avance en el desarrollo institucional de los derechos humanos dentro del sistema de las Naciones Unidas. Asimismo, se verá cuál es su importancia para la promoción de los derechos humanos a nivel internacional y cuáles son sus retos para el futuro.

\section{LA CREACión del Consejo de Derechos Humanos dentro DEL PROCESO DE REFORMAS DE LAS NACIONES UNIDAS}

La decisión de la Asamblea General de disolver la Comisión puede verse como una etapa de todo un proceso de reformas tanto de la propia Comisión como de las Naciones Unidas en general.

Desde su creación en 1947 la Comisión fue objeto de numerosas reformas

4 A la fecha de cierre del presente trabajo, 31 de agosto de 2007,5 períodos de sesiones ordinarios y 4 extraordinarios. 
en cuanto a su composición, funciones y mecanismos, basadas en el pragmatismo que caracterizó su trabajo a lo largo de los años y que hizo posible la constante adecuación y ampliación de sus tareas a los fines de tutela de los derechos humanos ${ }^{5}$. Se puede decir que la historia de la Comisión fue en sí todo un proceso de reformas que solo cesó con su disolución.

A nivel del sistema de las Naciones Unidas, recién en los últimos 10 años han tomado más fuerza iniciativas de reforma amplia $^{6}$ y han tenido lugar a los debates correspondientes, sin que hasta la fecha se haya llegado a un acuerdo. Uno de los últimos intentos de reforma extensa fue iniciado por el entonces Secretario General, Kofi Annan, en el segundo período de su mandato y abarcó temas cruciales para la Organización: seguridad internacional, derechos humanos, eliminación de la pobreza y medio ambiente. Así, el 21 de marzo de 2005 presentó a la Asamblea General un informe considerado por él mismo como ambicioso titulado «Un concepto más amplio de la libertad: Desarrollo, Seguridad y Derechos Humanos para todos» ${ }^{7}$.

5 Véase Buergenthal, Thomas (1995), International Human Rights in a Nutshell, pp. 79 ss.

6 El proceso de reformas sustanciales empezó ya en 1992 con el Secretario General Boutros Boutros-Ghali, sobre todo en el área del mantenimiento de la paz. Véase $\mathrm{su}$ informe "Un programa de Paz», (A/47/277-S/24111), accesible en español: $<$ http://www.cinu.org.mx/onu/reforma cs/a48_264/add04.pdf>, visitado el 24 de agosto de 2007.

7 Propuesta basada en los informes de 2 comisiones: un panel de alto nivel creado
En cuanto a los derechos humanos, Koffi Annan propuso toda una serie de cambios en el sistema de derechos humanos con el fin de reforzarlo y hacerlo más eficiente ${ }^{8}$. Uno de ellos, el más trascendental, es la disolución de la Comisión de Derechos Humanos y su sustitución por un Consejo dotado de atribuciones más amplias y que actúe con mayor determinación y eficiencia que aquélla9 ${ }^{9}$ Como razón de su disolución hace suyas una serie de críticas

en 2003 («High-Level-Panel on Threats, Challenges and Change») integrado por 16 expertos y otro grupo, dirigido por Jeffrey Sachs, compuesto de 240 economistas y expertos en desarrollo, que estudiaron el Proyecto del Milenio. En síntesis propone 3 medidas: cambiar la Comisión de Derechos Humanos; ampliar a 25 el número de miembros del Consejo de Seguridad dejando intacto el sistema de veto; y ampliar el presupuesto a su servicio. Véase A/59/2005, párr. 4 ss., accesible en español: <http://millenniumindicators. un.org/unsd/mispa/mi_links.aspx - visitado el 24 de agosto de 2007>. Véase también la nota explicativa del Secretario General: A/59/2005/Add.1. Del informe presentado al $59^{\circ}$ periodo de sesiones de la Asamblea General sólo tuvo trascendencia la propuesta de reforma en materia de derechos humanos.

8 Entre los más importantes están la integración de los derechos humanos en el área de mantenimiento de la paz y en todo el sistema de las Naciones Unidas, el reforzamiento de la Oficina del Alto Comisionado para los Derechos Humanos y el aumento de la eficiencia de los órganos convencionales de protección de los derechos humanos. Véase „Un concepto más amplio de libertad «, A/59/2005 (nota 7), párr. 140 ss.

9 Véase A/59/2005 (nota 7), párr. 183. 
Ma. Cecilia AÑaños MeZa • El Consejo de Derechos Humanos de Naciones Unidas...

a la Comisión que en realidad han sido bastante conocidas por expertos, funcionarios y el mundo académico. La pregunta de si había necesidad de sustituirla por un nuevo órgano, lo que trae consigo grandes costos en tiempo y esfuerzos e implica a la vez cargas en el presupuesto, podrá responderse cuando examinemos más de cerca los cambios que ha acarreado la creación del Consejo.

En su Cumbre Mundial de 2005 para celebrar el sexagésimo aniversario creación de las Naciones Unidas, la Asamblea General aprobó el informe de Annan precisamente en lo relativo a la reforma del mecanismo de derechos humanos ${ }^{10} \mathrm{y}$ ordenó que se iniciaran negociaciones para darle forma concreta. Estas concluyeron unos meses más tarde con la Resolución 60/251, que sienta las bases para el establecimiento del Consejo de Derechos Humanos ${ }^{11}$.

10 Que apuntan en concreto a reforzar la Oficina del Alto Comisionado de las $\mathrm{Na}$ ciones Unidas para los Derechos Humanos, hacer más eficientes los órganos convencionales de protección de los derechos humanos y, por último, crear el Consejo de Derechos Humanos. Véase Documento Final de la Cumbre Mundial, A/RES/60/1; párrafos 15, 124 ss., 157 ss., accesible en español en: <http://www.ohchr.org/spanish/bodies/hrcouncil/docs/ gaA.RES.60.1_Sp.pdf>, visitado el 20 de agosto de 2007.

11 El texto fue originariamente una iniciativa del gobierno suizo, elaborado por el catedrático suizo Walter Kälin, miembro del Comité de Derechos Humanos y Representante del Secretario General de las Naciones Unidas para los derechos huma-

\section{La Comisión. Su importancia HISTÓRICA EN EL DESARROLLO DE LOS DERECHOS HUMANOS. SUS PROBLEMAS}

La Comision ${ }^{12}$ fue creada con el fin específico de abocarse a elaborar normas de derechos humanos. Así, obtuvo el mandato de redactar una Carta de Derechos Humanos, declaraciones o convenciones internacionales sobre los derechos civiles, la situación de la mujer, libertad de información y cuestiones similiares, así como de encargarse de la protección de las minorías y de la prevención de la discriminación ${ }^{13}$. Poco después se amplió su mandato a otros asuntos de derechos humanos no comprendidos dentro del mandato específico ${ }^{14}$.

Para el cumplimiento de sus funciones estaba facultada para crear órganos subsidiarios de apoyo tales como rela-

nos de las personas desplazadas al interior de los países.

12 Órgano subsidiario y especializado del ECOSOC creado por Res. 5 (I) ECOSOC del 16 de febrero de 1946 con arreglo al Art. 68 de la Carta de las Naciones Unidas. Compuesto por representantes de Estados que a lo largo de los años aumentaron de 18 a 53. En sesión plenaria del 27 de marzo de 2006 acordó su disolución al 16 de junio de 2006 y remitió los asuntos pendientes al Consejo, que se reuniría por primera vez el 19 de junio de 2006 . Véase más detalles sobre la Comisión en Alston, Philip (ed.), (1992), «The Commission on Human Rights», The United Nations and Human Rights, pp. 126/210.

13 Res. 5(1) ECOSOC del 16 de febrero de 1946, párr. 2.

14 Res. 9 (II) ECOSOC del 21 de junio de 1946, párr. 1. 
tores, expertos independientes, grupos de trabajo y subcomisiones, y de formular propuestas y recomendaciones. En la práctica la Comisión dio buen uso a estas facultades entendiéndose a la vez como órgano funcional o profesional dentro de las Naciones Unidas. Por lo demás, como órgano subsidiario del ECOSOC tenía el deber de presentar informes a este y toda propuesta o reforma que implicara carga para el presupuesto debía se aprobada por él.

En la práctica, la Comisión desempeñó un rol muy importante como codificadora en el desarrollo del derecho internacional de los derechos humanos. La declaración Universal de Derechos $\mathrm{Hu}$ manos, los Pactos Internacionales sobre Derechos Civiles y Políticos y Derechos Económicos, Sociales y Culturales, las Convenciones sobre Genocidio, Mujer, Niño, Discriminación racial, Tortura, Protección de las Minorías, así como los defensores de los derechos humanos son productos de su trabajo codificador. También contribuyó, aunque en muy pocas ocasiones, a esclarecer cuestiones conceptuales tales como la situación de los desplazados internos.

Después de haber concluido en 1967 la elaboración de los dos Pactos Internacionales, se dedicó con mayor intensidad a crear y desarrollar mecanismos necesarios y adecuados para responder efectivamente a denuncias individuales o comunicaciones privadas sobre violaciones de los derechos humanos ${ }^{15}$.

15 Res. 8 (XXIII) CHR del 16 marzo de 1967, mediante la cual se autoriza a la Subcomi-
Así, creó y desarrolló mecanismos de control, vigilancia y aplicación de los estándares iusinternacionales en materia de derechos humanos, tales como los procedimientos especiales y el $1503 \mathrm{o}$ confidencial, este último basado en la reserva al examinar los problemas de derechos humanos del Estado afectado. En el marco de estos procedimientos desarrolló cierta libertad de acción respecto del ECOSOC y se orientó a crear una atmósfera de diálogo y cooperación con el Estado comprometido en violaciones de los derechos humanos. En algunos casos emitió resoluciones sobre países, como las relaciones con el Apartheid en Sudáfrica y las desapariciones forzadas durante las dictaduras en Sudamérica, y en otros ofreció a los Estados cooperantes asistencia técnica y financiera a fin de mejorar la situación de los derechos humanos en el país afectado.

Ya desde 1977 con la entrada en vigor de los pactos internacionales antes mencionados hubo intentos de racionalización de la Comisión ${ }^{16}$, pero debieron pasar muchos años para que las Naciones Unidas declararan que ello era una necesidad. Fue así como, la Declaración de Viena, de 1993, reafirmó la necesidad de fortalecer y racionalizar los mecanismos de la Comisión ${ }^{17}$. A

sión para preparar informes anuales sobre violaciones de los derechos humanos utilizando información de diversas fuentes.

16 Cfr. Irmscher (2002): 244 ss, Decisión de la Comisión 4 (XXXIII), en: Report of the 33rd session, (E/5927, E/CN.4/1257 (1977), Chapter XXII, section B., p. 89). 17 Declaración de Viena y Programa de Acción (A/CONF.157/23), párr. 95, accesible 
raíz de ello se inició todo un proceso de reforma sustancial, tanto de sus mecanismos como de sus órganos a fin de hacerlos más eficaces y contrarrestar la polarización, aplicando los principios de objetividad y razonabilidad. Este proceso de reforma culminó en el año 2000 con la Res. De 2000/3 ECOSOC, que modificó el procedimiento $1503^{18}$.

A través de los años aumentó la importancia de las actividades creadas y desarrolladas por la Comisión. La ampliación del número de sus miembros a 53 Estados y el hecho de que no solamente se dedicara a la labor codificadora sino también a dar respuesta a las numerosas denuncias de violaciones de los derechos humanos en el mundo mediante los mecanismos desarrollados, la convirtió en el órgano de derechos humanos más importante de la organización, al punto que actúo prácticamente como una Asamblea General de los Derechos Humanos ${ }^{19}$.

en español en: <http://www.cinu.org.mx/ temas/dh/decvienapaccion.pdf>, visitado el 19 de agosto de 2007.

18 E/2000/INF/2/Add. La Comisión aprobó las propuestas del Grupo de Trabajo abierto entre período de sesiones que se creó en 1999 para dedicarse a la labor reformadora. Sus propuestas referentes al procedimiento 1503 fueron: mantener la confidencialidad, renunciar a la subcomisión, rotar a los miembros de los 2 Grupos de Trabajo y ampliar las funciones de la Oficina del Alto Comisionado para los Derechos Humanos dándole atribuciones de decisión sobre la admisibilidad del procedimiento 1503.

19 Cfr. BAUM (2000): 78.
Participaban en este foro central diplomático de derechos humanos no solo Estados miembros y no miembros, sino organizaciones intergubernamentales regionales, organizaciones no gubernamentales e instituciones de derechos humanos. Con ello, creció paralelamente su importancia política y su autoridad en el tratamiento de los derechos humanos a nivel mundial.

Estos son a grandes rasgos los logros de la Comisión y a partir de ellos seguirá actuando el Consejo. Mas debe tenerse también presente su lado negativo, que servirá de indicador para futuras evaluaciones de su labor.

\section{Problemas y criticas}

Dejando de lado su tinte absoluto y enfático, las críticas de Kofi Annan a la Comisión -falta de credibilidad y de profesionalidad, selectividad y polarización en el tratamiento de los derechos humanos, instrumentalización de la Comisión y degeneración en un foro de politización de los derechos humanos ${ }^{20}$ son acertadas.

Como entidad del ECOSOC, a lo largo de los años la Comisión se trasfor-

20 «En particular, ha habido Estados que se han hecho miembros de la Comisión no para afianzar los derechos humanos sino para protegerse contra las críticas o para criticar a otros. Esas tendencias han tenido como resultado la acumulación de un déficit de credibilidad que empaña la reputación de todo el sistema de las Naciones Unidas.» Un Concepto más Amplio de Libertad» (nota 7), párr. 182. 
mó de un órgano funcional codificador en uno político de importancia para ventilar los problemas de derechos humanos del mundo, al mismo tiempo que en uno de los órganos más politizados después del Consejo de Seguridad. Asimismo, el incremento del número de miembros a 53 Estados no solo le dió mayor representatividad sino que hizo más difícil y complicado llegar a acuerdos en materias sensibles de derechos humanos. Y de llegar a acuerdo se fueron tomando más sobre la base de la oportunidad política que de conformidad con los principios de la Carta. Estos hechos indudablemente afectaban la equidad, imparcialidad y eficacia que se esperaba de un órgano internacional de derechos humanos. No era pues causa de sorpresa que en la Comisión los Estados llevaran a nivel multilateral sus intereses particulares y regionales y sus rivalidades interestatales. La conformación de bloques para obtener la mayoría necesaria para investigar a un Estado por violaciones de derechos humanos fue solo una consecuencia natural de ello.

El pragmatismo de la Comisión, que trajo consigo ventajas para el desarrollo y adecuación de los mecanismos de derechos humanos a los cambios del sistema internacional, tuvo también la desventaja de que estos pasaran a ser engorrosos, pesados y complicados, lo que afectó su eficacia.

La selectividad en responder a unos casos de violaciones de los derechos humanos y a otros no, es un aspecto característico de la naturaleza política de un órgano como la Comisión, que solo puede reducirse, pero no eliminarse. Sin embargo, selectividad, polarización e ineficacia no solo caracterizan las actuaciones de la Comisión sino del sistema de las Naciones Unidas en general. Para ello basta dar una mirada al Consejo de Seguridad, la Asamblea General o la Secretaría General. El balance negativo de Annan sobre la Comisión fue abrumador y acentuado a fin de asegurar la aprobación de su proyecto de reforma de las Naciones Unidas, o por lo menos de su proyecto de creación del Consejo, pues este tenía mejores posibilidades de ser aprobado por la Asamblea General.

Téngase también presente que especialmente en sus últimos años, la Comisión enfrentaba problemas de creciente sobrecarga de trabajo que debía producir anualmente un número desmesurado de resoluciones ${ }^{21}$.

\section{FUNDAMENTO JURÍDICO, FINES, OBJETIVOS Y PRINCIPIOS DEL Consejo}

Al igual que la Comisión, la base jurídica del Consejo es la Carta de las Naciones Unidas, por lo cual se rige en primer término por sus principios y objetivos. En la Carta, los Estados miembros han asumido la obligación de respetar y contribuir a la realización de los derechos humanos ${ }^{22}$. En segundo lugar

21 Cfr. Hampson (2007): 8.

22 Véase el Art. 56 en conexión con el Art. 55 (c) de la Carta de Naciones Unidas. 
se encuentran la Declaración Universal de Derechos Humanos, la Declaración de Viena y las demás normas internacionales que forman parte del régimen de derechos humanos del Sistema. De ello se desprende que el alcance de su mandato es doblemente universal en el sentido de que se extiende a todos los Estados miembros de las Naciones Unidas, sean o no partes de un tratado internacional de derechos humanos, y a todos los derechos humanos.

\section{Fines}

El fin primario del Consejo radica en „Asegurar el disfrute efectivo por todas las personas de todos los derechos humanos, es decir, los derechos civiles, políticos, económicos, sociales y culturales, incluido el derecho al desarrollo» ${ }^{23}$. Están llamados a realizar este fin, en primer lugar los Estados miembros de las Naciones Unidas y la comunidad internacional en general, y en segundo lugar, todo el sistema operativo de las Naciones Unidas.

\section{Objetivos}

Del texto de la Resolución de creación del Consejo podemos identificar cuatro objetivos específicos que el Consejo está llamado a realizar:

23 A/RES/60/251 (nota 2), párrafo 12 del preámbulo.
2.1. Contribución al desarrollo del derecho internacional de los derechos humanos ${ }^{24}$

Este objetivo podrá alcanzarse mediante labores de creación normativa, desarrollo conceptual y sistematización del ya complejo y enredado cuerpo de normas de derechos humanos del sistema de las Naciones Unidas. Al respecto, el Consejo recibe un mandato amplio en comparación con el que tenía la Comisión, y su tarea de importancia no estará en crear más normas sino en desarrollar las existentes, es decir, darles contenidos definidos mediante tareas de conceptualización e interpretación y sistematizarlas para que formen un cuerpo normativo de derechos humanos coherente y unitario, lo que resultará en mayor claridad, transparencia, fuerza normativa y seguridad jurídica en el plano internacional. A su vez ello facilitará su aplicación al reducirse los polos de interpretación individual de las normas internacionales de derechos humanos por los Estados.

\subsection{Promoción del respeto de los} derechos humanos

El párrafo 2 de la Resolución dice: «...el Consejo será responsable de promover el respeto universal por la protección de todos los derechos humanos y libertades fundamentales de todas las

24 A/RES/60/251 (nota 2), párr. 5 (c). 
personas, sin distinción de ningún tipo y de una manera justa y equitativa ${ }^{25}$.

El texto citado ratifica la idea fundamental que rige en las Naciones Unidas en cuanto a los derechos humanos: el de promover su respeto y $\log \mathrm{O}^{26}$. Sin embargo, una leída ligera del texto puede traer alguna confusión entre los términos "promoción» $\mathrm{y}$ "protección". Solo el primero obliga al Consejo; el segundo es una obligación dirigida directamente a los Estados. Las Naciones Unidas no poseen el mandato de proteger los derechos humanos, por ello tampoco se puede esperar que establezcan mecanismos jurídicos para aplicarlos y observarlos, cosa que además desbordaría toda posibilidad material tratándose de un órgano de alcance universal como el Consejo. $\mathrm{Si}$ el sistema de las Naciones Unidas habla de «protección» debe entenderse que se trata en primer lugar de una obligación propia de los Estados que solos o en conjunto creen un sistema jurídico e institucional, nacional y regional eficaz que garantice el respeto de los derechos humanos en sus respectivos países.

Todas las actividades del Consejo deberán examinarse y evaluarse de acuerdo con sus objetivos. Por ello, se hace necesario que estén bien definidos. Para lograr la promoción del respeto universal de los derechos humanos, la tarea del Consejo se limita a estar en constante diálogo y conversación con

$25 \mathrm{~A} / \mathrm{RES} / 60 / 251$ (nota 2).

26 Art. 55 de la Carta de las Naciones Unidas. el Estado afectado poniendo en marcha los mecanismos a su disposición a fin de mejorar la situación de los derechos humanos en el país, ya sea creando normas protectoras o instituciones defensoras de los derechos humanos, o ya educando en los derechos humanos. Por lo general las mejoras que se han de lograr son de largo alcance, hecho que hay que recordar al formular críticas al Consejo por su falta de reacción a situaciones de emergencia en la materia.

\subsection{Contribución a la prevención de violaciones de los derechos humanos ${ }^{27} \mathrm{y}$ al mejoramiento de las situaciones de violación de estos incluyendo las violaciones graves y sistemáticas.}

Los aportes del Consejo frente a violaciones de los derechos humanos en el mundo serán precisamente prevenir futuras violaciones de los derechos humanos y lograr una mejoría sustancial de la situación de estos en los Estados que se señala a su atención. No es objetivo del Consejo poner remedio a tales violaciones o socorrer a las víctimas. El Consejo trabajará en pos de este objetivo, no como instancia fiscalizadora, juzgadora o coactiva, sino a partir del principio de cooperación y diálogo. En caso de que el Estado no coopere y el diálogo fracase, se prevén sanciones de carácter político como la de seguir observando al Estado en un procedimiento público

27 A/RES/60/251 (nota 2), párr. 5 (f). 
y, si fue miembro del Consejo, excluirlo de él si se comprueba que es responsable de violaciones graves y sistemáticas de los derechos humanos.

\subsection{Contribución al reforzamiento y racionalización del sistema de derechos humanos de las Naciones Unidas ${ }^{28}$.}

El Consejo fue creado a fin de reforzar y racionalizar el sistema de derechos humanos de la organización. En este contexto, reforzar no solo implica crear nuevas normas, instituciones, mecanismos y aumentar el presupuesto, sino también que los derechos humanos estén integrados en las demás actividades de las Naciones Unidas. En este último caso, no está claro cómo y en qué medida se ha de lograr esta «integración». Cierto es que al momento de tomar decisiones los demás órganos tendrán que considerar las normas internacionales vigentes de derechos humanos. Más aquí debe primar la cautela de que la integración se desea solo en cuanto a normas desarrolladas que posean validez y una vez haya tenido lugar el proceso de racionalización.

En cuanto a la racionalización, esta se ha convertido en una necesidad para todo el sistema de las Naciones Unidas y es el objetivo de todo plan serio de reforma. La Declaración y Programa

28 A/RES/60/251 (nota 2), párr. 12 del preámbulo. de Acción de Viena ${ }^{29}$ la incluye como una exigencia para todos los órganos de derechos humanos de la organización. El proceso recién se inicia y aún no pueden detectarse resultados positivos satisfactorios. Refiriéndose al Consejo, existen dos aspectos de racionalización. Uno interno, que se lleva a cabo dentro del mismo mediante la revisión y perfeccionamiento de los mandatos, mecanismos, funciones y responsabilidades emanadas de la Comisión y asumidos por él y los nuevos que establezca. El otro tiene lugar entre el Consejo y los demás órganos de las Naciones Unidas que se ocupan de los derechos humanos, para lo cual el texto se refiere a una "coordinación eficaz» ${ }^{30}$. En ambos aspectos, el tema de la racionalización queda aún por resolver.

\section{Los principios}

En su párrafo 4, el texto que crea el Consejo enumera la universalidad, imparcialidad, objetividad, no-selectividad, diálogo internacional constructivo y cooperación internacional que deben guiar su labor y los eleva a la categoría de principios. Mas estos principios no

29 Declaración de Viena y Programa de Acción (nota 17), párr. 11 del preámbulo, párrafo dispositivo 1.

30 A/RES/60/251 (nota 2), párr. 6 y 3. El Consejo promoverá «la coordinación eficaz y la incorporación de los derechos humanos en la actividad general del sistema de Naciones Unidas». 
están definidos en el texto indicado, cosa comprensible por tratarse de un documento marco que crea un órgano institucional. La Resolución 5/1 del Consejo relativo a la formación institucional, tampoco arroja luces al respecto ya que se limita a repetirlos. Con el fin de evitar interpretaciones subjetivas o su instrumentalización, la tarea de darles un contenido cierto y definido queda a la Asamblea General o al Consejo.

Cabe señalar que se trata de mandatos de carácter normativo en que el Consejo es destinatario para su cumplimiento. Mas estos principios no constituyen una innovación en el texto en mención, sino que son el producto del desarrollo y evolución del trabajo de muchos años de la Comisión y demás órganos de derechos humanos de las Naciones Unidas para que su labor alcance un estándar mínimo ${ }^{31}$. Están plasmados en numerosos textos internacionales de derechos humanos y se encuentran cimentados en toda actividad internacional de derechos humanos, sea universal o regional, dentro y fuera de las Naciones Unidas ${ }^{32}$.

31 No hay mención expresa en la Carta de Naciones Unidas ni en la Declaración Universal de Derechos Humanos. Recién la Declaración de Viena (nota 17), párr. 32, los menciona.

32 Organizaciones internacionales no gubernamentales tales como el Comité de la Cruz Roja Internacional, Amnistía Internacional, Human Rights Watch, Terres des Hommes, se rigen por los principios de universalidad, imparcialidad y objetividad.
La Declaración y Programa de Acción de Viena, en su párrafo 32, se refiere a la universalidad, objetividad y no selectividad como garantías para el tratamiento de los asuntos de derechos humanos y en su párrafo 39 hace referencia a la importancia de la imparcialidad de la información en materia de derechos humanos ${ }^{33}$. Otros documentos que incorporan estos principios son: la Resolución que crea la Oficina del Alto Comisionado para los Derechos Humanos ${ }^{34}$; la Plataforma de Acción de la IV Conferencia de los Derechos de la Mujer aprobada en Beijing, China $^{35}$; la Declaración con motivo del cincuentenario de las Naciones Unidas ${ }^{36}$; la Declaración sobre el Derecho al Desarrollo ${ }^{37}$; el Protocolo Facultativo de la Convención contra la Tortura ${ }^{38}$ y últimamente el Código de Conducta de los Procedimientos Especiales, elaborado por el Consejo ${ }^{39}$.

Si bien estos principios adquieren un cimiento sólido en la labor de derechos

33 Declaración de Viena y Programa de Acción (nota 17).

34 A/RES/48/141, párr. 8 del preámbulo.

35 Véase informe: A/CONF.177/20, párr. 212.

36 A/RES/50/6, párr. 10.

37 A/RES/51/99 (3.03.1997), párr. 13 del preámbulo.

38 A/RES/57/199, Art. 2 (3). Entrada en vigor: 22 de junio de 2006 .

39 Resolución 5/2 del 18 de junio de 2007, aprobada en su quinto período de sesiones, en: A/HRC/5/L.11, p. 45 ss., accesible en inglés en: <http://www.ohchr.org/english/bodies/hrcouncil/docs/5session/A. HRC.5.21_AEV.pdf>, visitado el 221 de agosto de 2007. 
Ma. Cecilia AÑaños Meza • El Consejo de Derechos Humanos de Naciones Unidas...

humanos en el sistema de las Naciones Unidas con la Resolución de Asamblea General sobre el «Fortalecimiento de las actividades de las Naciones Unidas en la esfera de los derechos humanos mediante el fomento de la cooperación internacional, e importancia de la no selectividad, la imparcialidad y la objetividad» ${ }^{40}$, se puede ver también que hay una falta de clarificación de los mismos.

Por otro lado, se puede aducir que estos principios están reconocidos en documentos que en su mayoría constituyen soft law. Esta objeción no es de inquietar si se tiene en cuenta que están en pleno desarrollo normativo iusinternacional y en vías de formar parte del derecho consuetudinario internacional o de servir como principios generales de derecho reconocidos por las naciones civilizadas $^{41}$. Sin lugar a dudas, el principio de imparcialidad se halla dentro del segundo caso. El lado flojo, como se anotó, está en la imprecisión de sus contenidos y alcance.

Desde luego, mientras que el principio de universalidad exige que los derechos humanos sean válidos para todos los seres humanos, la imparcialidad como principio general y garantía procesal del derecho nacional exige desprenderse de todo prejuicio, intere-

40 A/RES/59/190, accesible en español en: $<$ http://ap.ohchr.org/documents/alldocs. aspx?doc_id=12060>, visitado el 24 de agosto de 2007.

41 Véase el Art. 38 párr. 1 (b) y (c) del Estatuto de la Corte Internacional de Justicia. ses, o sentimientos ${ }^{42}$. Mientras que la objetividad exige realizar un análisis o examen a partir de métodos objetivos establecidos y llegar a resultados a que otros también llegarían al analizar el mismo caso, la no-selectividad prohíbe la selección de casos por motivos de interés político u oportunismo.

En la práctica de la Comisión tmbién se considera tanto el diálogo internacional constructivo, que exige determinadas pautas para llegar a un consenso universal ${ }^{43}$, como la cooperación internacional que es base del sistema de derechos humanos de las Naciones Unidas, pero no siempre fueron practicados con éxito. El texto de creación del Consejo solo los confirma una vez más. El principio de diálogo constructivo precisamente uno de los más difíciles de realizar en la práctica actual del Consejo, como se puede ver de sus primeras sesiones especiales al tratar temas delicados como los conflictos de Palestina, Líbano y Sudán ${ }^{44}$,

42 La Convención Europea de Derechos Humanos en su Art. 6 reconoce la imparcialidad como derecho de toda persona al debido proceso. Una de las máximas de acción de organizaciones no gubernamentales tales como Amnistía Internacional, Human Watch, Médicins sans Frontières, entre otras, era la imparcialidad de sus informes.

43 Comp. Watson (2004): 54-58. Accesible en Internet: <http://www.ci.hs.iastate.edu/ prspstud/grad/Grad2/facultypages/Watson $\% 20$ et $\% 20$ al..pdf $>$, visitado el 10 de agosto de 2007.

44 Las resoluciones se han dado solo por mayoría y con un buen número de votos en contra. Véanse los informes de los 
convirtiéndose los debates en luchas por un consenso o bloqueo en que las posiciones políticas encontradas son rígidas y no admiten consenso.

\section{Estructura del Consejo}

El Consejo fue constituido como órgano auxiliar de la Asamblea General de acuerdo con las facultades que le otorga a esta el Art. 22 de la Carta de las Naciones Unidas. Lo que se perseguía con esto, era mejorar la posición del Consejo dentro del sistema de las Naciones Unidas, en comparación con la Comisión. Mas dentro de la normativa de la Carta no hay mejoría de posición puesto que al igual que la Comisión, el Consejo no es más que un "órgano auxiliar» de un órgano principal de las Naciones Unidas. Entre ambos órganos principales no hay relación de jerarquía sino de coordinación y según la Carta ambos tienen el mandato de ocuparse de cuestiones de derechos humanos, con la diferencia de que el ECOSOC posee un mandato específico y la Asamblea General uno general ${ }^{45}$.

La mejoría se detecta en los aspectos político y de eficacia, con consecuencias de cierta significación. El Consejo tiene ahora una relación directa con el «foro mundial» por antonomasia y con ello

primeros períodos extraordinarios de sesiones: A/HRC/S-1/3, A/HRC/S-2/2, A/ $\mathrm{HRC} / \mathrm{S}-3 / 2, \mathrm{~A} / \mathrm{HRC} / \mathrm{S}-4 / 5$.

45 Art. 62 (2) y Art. 10 de la Carta de las Naciones Unidas. mejora su peso político, pues rinde sus informes directamente a la Asamblea General y los Estados velarán por que sus problemas de derechos humanos no se ventilen en él. Se espera también un mayor respaldo político y financiero por la Asamblea General y su Quinta Comisión a iniciativas y propuestas del Consejo. Paralelamente, la Asamblea General controla y vigila directamente las acciones del Consejo y puede también ejercer influencia directa en él. El aspecto negativo radica en que el Consejo se torna mucho más propenso a las posiciones polarizantes y a las tensiones políticas propias de la Asamblea General, y corre mayor riesgo de ser instrumentalizado políticamente. Pensando en el objetivo de eliminar la politización y los dobles raseros que fueron argumentos que se emplearon para disolver la Comisión, la creación del Consejo como subsidiaria de la Asamblea General no significa ningún avance.

\section{Composición}

El Consejo cuenta con 47 representantes o enviados de los gobiernos de turno de sus países. Esto es, 6 miembros menos que la extinta Comisión. La reducción obedece al propósito de mejorar su capacidad de tomar decisiones al hacerlo más eficiente. Mas esta pequeña reducción cuantitativa en el número de miembros influirá muy poco en la eficacia de las decisiones, de por sí muy complicadas, precisamente por tratarse 
Ma. Cecilia AÑaños Meza • El Consejo de Derechos Humanos de Naciones Unidas...

de un ámbito cargado de controversias como los derechos humanos y de un foro de alcance universal.

Los Estados son elegidos de acuerdo con el principio de distribución geográfica equitativa: Africa y Asia cuentan con 13 miembros cada una; Europa del Este, 6; América Latina y el Caribe, 8 ; y Europa Occidental y otros Estados, $7^{46}$.

Esta nueva distribución geográfica ha traído consigo problemas de índole política para los Estados miembros al aumentar la atmósfera de tensión política entre los distintos grupos de países que integran el Consejo. Comparada con la distribución de asientos en la Comisión, el grupo de países occidentales y el de América Latina y el Caribe han perdido cada uno 3 asientos, resultando en una mejoría en el número de asientos de países de Asia y África. Estos, con 26 asientos, forman la mayoría necesaria para tomar decisiones en el Consejo. Los países occidentales en especial sienten una gran mella en su influencia, ya que se les hará más difícil sacar adelante propuestas que no tengan el respaldo del grupo asiático o africano. No es pues de sorprender que estos países busquen otras formas de compensar su pérdida numérica dentro del Consejo.

46 A/RES/60/251 (nota 2), párr. 7. Dentro del grupo de América Latina y el Caribe (GRULAC) fueron elegidos el primer año: Brasil (2), Argentina (1), México (3), Perú (2), Guatemala (2), Uruguay (3), Cuba (3) y Ecuador (1). España lanzará su candidatura para el año 2008.
Más las actividades del Consejo no se reducen a la participación de los 47 miembros. La importancia política de la Comisión en su tiempo y del Consejo ahora, radica en la participación de una amplia gama de representantes de la comunidad internacional como los demás Estados miembros de las Naciones Unidas en calidad de observadores y coauspiciadores ${ }^{47}$ organismos especializados, organizaciones internacionales de carácter regional, organizaciones nacionales de derechos humanos y organizaciones no gubernamentales ${ }^{48}$.

\section{La calidad de miembro del Consejo}

Para asegurar la credibilidad del Consejo se ha establecido un criterio cualitativo a los aspirantes a un asiento. Para ser miembro del Consejo, el Estado debe presentar su candidatura y mencionar sus contribuciones o aportes positivos a la promoción y protección de los derechos humanos. Asimismo, puede hacer voluntariamente promesas y compromisos en el campo de los derechos humanos a la Asamblea General,

47 Los Estados, pueden participar como observadores en las sesiones ordinarias del Consejo con derecho a uso de la palabra y como copatrocinante. Más detalles en Irmscher (2002): 52 ss.

$48 \mathrm{~A} / \mathrm{RES} / 60 / 251$ (nota 2), párr. 11; Regla 7 de las Reglas de Procedimiento del Consejo, A/HRC/5/L.11 (nota 37). El Consejo se basará en la Res. 1996/31 del ECOSOC del 25 de julio de 1996, en la Res. 2005/74 de la Comisión del 20 de abril de 2005 y en las prácticas de la Comisión. 
la que se encarga de elegir a los nuevos miembros por mayoría absoluta ${ }^{49}$.

Este criterio establecido para elegir los miembros convierte a la Asamblea General y sobre todo al Consejo en blanco de las críticas del grupo de Estados occidentales y de organizaciones no gubernamentales, para quienes estas condiciones son insuficientes ya que permiten que sean miembros del Consejo Estados cuestionados en materia de derechos humanos. Estas críticas pasan al plano de la acción cuando ejercen presión para que mejore la calidad en la composición del Consejo, por ejemplo, no admitiéndose o excluyéndose a Estados que tienen un récord negativo en derechos humanos. Este hecho será una constante y probablemente hará que tanto el Consejo como la Asamblea General justifiquen la participación.

De los miembros elegidos en el primer año de funcionamiento del Consejo aproximadamente la mitad o por lo menos un buen número de Estados tenían sistemas políticos democráticos deficitarios o carecían de ellos. De aplicarse rigurosamente el criterio de calidad, tal como lo exigen los países occidentales, quedarían vacíos numerosos de sus asientos. Para que el Consejo cumpla su función de promover

49 A/RES/60/251 (nota 2), párr. 7 y 8. El gobierno de Estados Unidos retiró su candidatura por considerar, entre otros puntos, que los criterios de elección eran insuficientes. Más detalles en nota de prensa <http://www.un.org/News/Press/ docs/2006/ga10449.doc.htm>, visitado el 19 de agosto de 2997. el respeto universal de los derechos humanos, no debe reducirse a «un club selecto de democracias ejemplares» que dé las pautas universales por las que deben regirse los demás Estados del mundo -que las considerarán como una imposición o exportación de modelos, ideas y valores occidentales. Ello sería contrario al principio de diálogo constructivo y despojaría al Consejo de toda representatividad, y por ende de la legitimidad ${ }^{50} \mathrm{y}$ autoridad universales de que goza, con todas las críticas que se hagan a su credibilidad.

La finalidad del Consejo es trabajar a partir de los estándares mínimos de derechos humanos, en lo posible con la participación de todos los Estados, para que se proyecte la validez de estos. La posición inflexible, juzgadora y excluyente de la mayoría de los países occidentales no contribuye al diálogo, sino lo dificulta. La inclusión de Estados cuestionados aumenta en cambio las opciones de que estos se pongan al paso de las exigencias internacionales en esta materia, lo que implica también que los Estados occidentales entren en diálogo con ellos. Yendo aún más lejos, pensamos que la elección debió ser más democrática y haber permitido que se rotaran todos los miembros de las Naciones Unidas sobre la base del principio de igualdad soberana, y así evitar la selección y permanencia en él de solo algunos Estados. Puede verse ya que en el futuro determinados Estados se convertirán de facto en miembros

\footnotetext{
50 Véase también Theissen (2006): 146.
} 
Ma. Cecilia AÑaños MeZa • El Consejo de Derechos Humanos de Naciones Unidas...

causipermanentes y en cambio otros no tendrán la opción de formar parte de él en un futuro previsible.

\section{Reelección}

Un miembro puede ser reelegido solo una vez, es decir, solo puede ocupar un asiento en el Consejo por dos periodos consecutivos. Esto posibilita cierta rotación y variación de los miembros, necesaria en vista del vasto número de Estados miembros de las Naciones Unidas. Esta variación puede considerarse como un modesto paso de democratización si se compara con la Comisión, que permitía la reelección inmediata sin restricciones, hecho que fue muy bien aprovechado por potencias occidentales partes del Consejo de Seguridad, que de hecho se constituyeron en miembros permanentes o cuasi permanentes de ella.

\section{Pérdida de la calidad de miembro}

Un Estado miembro del Consejo puede ser suspendido de su calidad de tal si es declarado responsable de violaciones graves y sistemáticas de los derechos humanos por votación de dos tercios de los miembros presentes de la Asamblea Gene$\mathrm{ral}^{51}$. El problema es determinar cuándo un Estado es responsable de violaciones graves de los derechos humanos, porque no está claro de qué criterios de exclusión

51 A/RES/60/251 (nota 2), párr. 8. se valdrá la Asamblea. Uno de ellos podría ser el resultado del procedimiento 1503 reformado, cuya tarea es identificar situaciones de violaciones graves de los derechos humanos. Naturalmente, los Estados miembros del Consejo que son objeto del procedimiento confidencial, están expuestos a un proceso de exclusión. Por lo pronto, de surgir un caso de exclusión, dependerá principalmente de la oportunidad política.

\section{FunCIONES}

Como se dijo, el Consejo tiene la facultad de examinar la situación de los derechos humanos en todo el mundo, teniendo presentes sus características esenciales de universalidad, indivisibilidad, interdependencia y complementariedad. Asimismo, de acuerdo con los objetivos antes señalados, se le asignan al Consejo determinadas funciones en tres ámbitos de actividad:

1. Ámbito normativo o conceptual de los derechos humanos, esto es, fijación de normas. En esta materia el Consejo continuará la labor de la Comisión, como lo ha hecho ya en su primer año de sesiones ${ }^{52}$.

2. Ámbito de promoción. Incluye una variada gama de actividades. La primera

52 Aprueba la Convención Internacional para la protección de todas las personas contra las desapariciones forzadas, A/HRC/ RES/1/1 y la Declaración de las Naciones Unidas sobre los derechos de los pueblos indígenas, $\mathrm{A} / \mathrm{HRC} / \mathrm{RES} / 1 / 2$, ambos de 29 de junio de 2006. 
de ella es la promoción de la educación y conocimiento de los derechos humanos, para lo cual será necesaria una buena coordinación con la UNESCO, que se ocupa del derecho a la educación. El Consejo suministrará también a los Estados asesoramiento, asistencia técnica y fomento de capacidades, tareas que caen propiamente dentro de la cooperación para el desarrollo. Otras tareas de promoción son: servir de foro de diálogo sobre cuestiones realizadas con las temáticas de derechos humanos; promover el pleno cumplimiento por parte de los Estados de sus obligaciones internacionales en materia de derechos humanos; llevar a cabo su seguimiento; realizar exámenes periódicos sobre cada Estado; contribuir al diálogo y cooperar en la prevención de violaciones de los derechos humanos; cooperar estrechamente con los gobiernos, instituciones nacionales, regionales y con la sociedad civil; presentar informes anuales a la Asamblea General y formular recomendaciones sobre la promoción y protección de los derechos humanos; promover la coordinación eficaz y la integración de los derechos humanos en la actividad general del sistema de las Naciones Unidas.

3. Tratamiento de situaciones de violación de los derechos humanos. El texto de creación del Consejo dice: «[..] el Consejo deberá ocuparse de las situaciones en que se violen los derechos humanos, incluidas las violaciones graves y sistemáticas, y hacer recomendaciones al respecto $»^{53}$. Esta

$53 \mathrm{~A} / \mathrm{RES} / 60 / 251$ (nota 2), párr. 3. tarea se cumplirá con ayuda de los mecanismos ya existentes, como son los procedimientos especiales temáticos y por país, el asesoramiento de expertos y el procedimiento de denuncias o 1503, con la tarea adicional de revisarlos ${ }^{54}$. Aquí la labor del Consejo es sobre todo de carácter preventivo de futuras violaciones, de observación y de vigilancia.

Problemas de carácter ético y práctico se presenta con su tarea de «responder con prontitud a situaciones de emergencia de derechos humanos» ${ }^{55}$. La cuestión que surge es en qué momento y cómo ha de responder a estas emergencias. En su breve práctica el Consejo solo ha respondido a conflictos armados que han llamado la atención de los medios de comunicación y de los políticos, y su intervención ha sido criticada por grupos occidentales. En realidad hubo situaciones de gravedad que no fueron objeto de una intervención especial, por ejemplo Irak, Afganistán, Somalia, Congo, Sri Lanka, Guantánamo, así como la ejecución por motivos políticos de Sadam Hussein y miembros de su gobierno. Aunque muchos de estos casos son observados por los relatores de los procedimientos especiales, el Consejo no realizó ninguna sesión extraordinaria

54 A/RES/60/251 (nota 2), párr. 6. El Consejo ha asumido el procedimiento confidencial 1503, el sistema de los relatores especiales y las reglas de participación de las ONGs.

55 A/RES/60/251 (nota 2), párr. 5 (f). De acuerdo con este mandato, en su primer año el Consejo ha celebrado 4 períodos extraordinarios de sesiones para examinar la situación en Palestina, Líbano y Sudán (Darfur). 
Ma. Cecilia AÑaños Meza • El Consejo de Derechos Humanos de Naciones Unidas...

ni emitió resoluciones como en los casos de Israel, Líbano y Sudán. Ello revela el tratamiento selectivo aplicado por el Consejo frente a situaciones de emergencia, así como la imposibilidad material de responder a todas las emergencias de derechos humanos que surgen en el mundo. Es un dilema que tienen por resolver tanto el Consejo como la Asamblea General, pues tiene consecuencias de importancia y trascendencia para el desarrollo del sistema de derechos humanos.

De lo descrito se puede ver que el mandato del Consejo es más amplio que el de la Comisión. Como el Consejo es un órgano que no funciona en forma permanente, para el cumplimiento satisfactorio de sus funciones tendrá que valerse de órganos subsidiarios, grupos de trabajo y relatores. Uno de ellos, creado por el Consejo como resultado de su formación institucional, es el Comité Asesor, que reemplaza a la Subcomisión y se compone de 18 expertos independientes que prestan apoyo al Consejo con conocimientos especializados basados en estudios e investigación.

La resolución que crea el Consejo prescribe también que su método de trabajo debe cumplir con un determinado estándar ético y profesional. Así pues, debe ser transparente, equitativo e imparcial y posibilitar un diálogo genuino; asimismo, debe orientarse a los resultados y permitir discusiones e interacción sustantiva entre los procedimientos especiales y los mecanismos de que dispone ${ }^{56}$.

56 A/RES/60/251 (nota 2), párr. 12. También
Ahora daremos una mirada a los mecanismos de apoyo del Consejo, a fin de poder comprender el alcance de sus funciones.

\section{Mecanismos de APoyo Del Consejo}

Los mecanismos que creó y desarrolló la Comisión sirven de punto de partida para la labor del Consejo. Además de incorporarlos, este recibió la tarea de revisarlos, desarrollarlos y racionalizarlos. El proceso de revisión ha durado un año y tuvo como resultado el documento «Institution-building of the United Nations Human Rights Council», que formará la base de su trabajo ${ }^{57}$. El documento, en concordancia es previsto con la Res. 60/251 de la Asamblea General, prevé los siguientes mecanismos:

\section{El examen periódico universal}

Se configura como nuevo mecanismo de vigilancia del Consejo. Consiste en examinar a «cada Estado» en el

párr. 105 de la Resolución 5/1, en: A/ HRC/5/L.11, accesible en inglés en: <http://www.ohchr.org/english/bodies/ hrcouncil/docs/5session/A.HRC.5.21_ AEV.pdf $>$, visitado el 21 de agosto de 2007, p.28.

57 Res. 5/1 del Consejo (nota 56). En él se incluyen además de los mecanismos y órganos de apoyo, el programa y métodos de trabajo, y las reglas de procedimiento. 
cumplimiento de sus obligaciones y compromisos internacionales de derechos humanos ${ }^{58}$. Aunque el texto de creación del Consejo no es claro al referirse a "cada Estado", de su contexto y por el carácter universal del examen se entiende que serán objeto de revisión todos los Estados miembros de las Naciones Unidas.

En su quinto período de sesiones el Consejo dio a conocer las pautas en que se basa este procedimiento ${ }^{59}$. El mismo estará a cargo de un Grupo de Trabajo compuesto de 47 representantes de los Estados miembros asistido por tres relatores elegidos entre ellos. Los primeros Estados objeto de examen son los miembros que permanecieron un año en él. El mecanismo es contínuo y funciona en ciclos de cuatro años. Dentro de cada ciclo deben haberse examinado todos los Estados, lo que implica revisar la situación de 48 Estados por año. Cada Estado será revisado en una audiencia o sesión de tres horas, ampliables a cuatro, la que concluirá con un informe que presentará conclusiones o recomendaciones ${ }^{60}$. Estas consistirán en pedir al Estado en cuestión que adopte medidas positivas o bien en ofrecerle apoyo técnico. En otros casos, el informe concluirá con la identificación de las violaciones de los derechos humanos cometidos por el Estado.

En el funcionamiento de este mecanismo juega un rol importante la

58 Comp. A/Res/60/251 (nota 2), párr. 5(e). 59 Res. 5/1, A/HRC/5/L.11 (nota 56), p. 4 ss.

60 Res. 5/1, párr. 11, en: A/HRC/5/LII (nota 56).
Oficina del Alto Comisionado para los Derechos Humanos, que se encarga de presentar al Consejo los dossiers de los países por examinar, con información proveniente de diversas fuentes fidedignas. El Estado examinado también proporcionará información y tiene derecho a réplica, a dar opiniones y a responder al informe.

Se entiende que este mecanismo, como evaluación del Estado basada en información proporcionada por el propio Estado, los relatores de los procedimientos especiales, los comités de derechos humanos, organizaciones no gubernamentales, demás organismos de las Naciones Unidas, etc., contribuirá a la visibilidad y transparencia del conjunto de obligaciones y compromisos internacionales contraídos por cada uno de los Estados y de lo que debe hacer en el futuro para darles cumplimiento y, de ser el caso, subsanar las deficiencias en materia de derechos humanos. Si la evaluación es realizada debidamente servirá de barómetro fidedigno del récord de derechos humanos de los Estados y será más que la suma o colección de informes, descartando a la vez el peligro de duplicación de tareas respecto de los informes y evaluación de los Estados de los procedimientos generales y especiales convencionales.

La gran ventaja de este procedimiento es su universalidad y la relevancia que pueden tener sus resultados. Sin embargo, el procedimiento creado por la Resolución 5/1 del Consejo arroja dudas sobre la funcionalidad del examen en la práctica. Las dudas radican específica- 
Ma. Cecilia AÑaños MeZa • El Consejo de Derechos Humanos de Naciones Unidas...

mente en la profundidad de la revisión. El Examen Periódico Universal que se concentra en un acto de algo más de tres horas, corre el peligro de ser superficial y un mero formalismo por el que pasarán todos los Estados. Ello menoscabaría su credibilidad y eficacia y por ende su peso político. Las dudas se extienden también a si el Consejo tiene las condiciones materiales para realizar el examen. El primer año de su puesta en práctica será indicador de su funcionalidad.

\section{Los procedimientos especiales}

Consisten en la investigación de situaciones de los derechos humanos por relatores especiales, expertos independientes o grupos de trabajo elegidos por el Consejo. Las investigaciones o estudios se realizan por temas o por país. En su quinto período de sesiones el Consejo renovó los mandatos de la Comisión, salvo los referidos a Belarús y Cuba, quedándose a cargo de 38 mandatos temáticos y por países ${ }^{61}$. La base legal de este procedimiento se encuentra en el Manual de Procedimientos Especiales de las Naciones Unidas y en el Código de Conducta para los Procedimientos Especiales ${ }^{62}$.

61 Véase la renovación de mandatos: Res. 5/1, appendix I en: A/HRC/5/L.11 (nota $56)$, p. 38. Sobre los mandatos de la Comisión: Villán Durán (1996): 337 ss.

62 Res. 5/2 del Consejo, en: A/HRC/5/1.11 (nota 39), p. 45.

\section{El procedimiento de denuncia}

De acuerdo con este procedimiento el Consejo tiene la prerrogativa de ocuparse de cuadros persistentes de violaciones graves de los derechos humanos cometidas en todo el mundo y que se hayan comprobado fehacientemente ${ }^{63}$. Para ello, retoma el procedimiento 1503 o confidencial establecido por la Res. 1503 (XLVIII) del ECOSOC del 27 de mayo de 1970 y revisada por la Res. 2000/3 del 19 de junio de $2000^{64}$. $\mathrm{Su}$ objetivo es esclarecer los hechos $\mathrm{y}$, de ser el caso, identificarlos como violaciones sistemáticas y graves de los derechos humanos, y mediante diálogo con el gobierno conseguir que mejore la situación en el país de que se trata ${ }^{65}$. Las violaciones graves de los derechos humanos deberán además tratarse en el contexto en que se produjeron.

En el Consejo el procedimiento seguirá funcionando con el apoyo de los dos grupos de trabajo que existían en la Comisión: el Grupo de Trabajo de Comunicaciones y el Grupo de Trabajo sobre Situaciones.

En la práctica el mecanismo ha demostrado ser eficaz precisamente por su confidencialidad y por el diálogo con el gobierno afectado que en estas condiciones está más dispuesto a colaborar con las Naciones Unidas. Pero también tiene puntos débiles, como ser su selectividad,

63 Res. 5/1, párr. 80, en: A/HRC/5/L.11 (nota 56), p. 19.

64 Res. 5/1, párr. 81, en: A/HRC/5/L.11 (nota 56), p. 19, norma de remisión.

65 Irmscher (2002): 357. 
lo enredoso, pesado y lento del procedimiento, la mediatización del individuo y la falta de control público ${ }^{66}$; aspectos negativos que el Consejo deberá tener presente para el desarrollo futuro del mecanismo.

Aunque la Resolución sobre la formación institucional del Consejo no menciona expresamente el conocido procedimiento 1235 o público, se entiende que este sigue vigente como opción del Consejo para actuar contra el Estado en caso de que el procedimiento confidencial fracase por falta de cooperación de este.

\section{LOS PERÍODOS DE SESIONES DEL Consejo}

El Consejo como órgano no permanente celebra reuniones periódicas para ocuparse de los temas de su mandato. A diferencia de la Comisión, que solo se reunía anualmente, debe reunirse tres veces al año por un mínimo de 10 semanas de sesiones. Asimismo, puede convocar períodos extraordinarios de sesiones para responder a situaciones de emergencia de derechos humanos, a petición de un Estado y con el apoyo de un tercio de los miembros, esto es, 15 miembros. En este caso, también sigue la práctica de la Comisión ${ }^{67}$.

66 Comp. Críticas al procedimiento, Irmscher (2002): 473 ss.

67 Por cierto una práctica breve en la Comisión. Recién en 1990 el ECOSOC autorizó a la Comisión para convocar períodos extraordinarios de sesiones en casos gra-
Con el aumento del número de sesiones, el Consejo dispone a primera vista de más tiempo para cumplir con su programa de trabajo y puede responder más rápidamente a las situaciones de emergencia de derechos humanos. Mas no debe olvidarse que el Consejo tiene un mandato mucho más amplio que el de la Comisión, por lo que no vemos que el mayor tiempo tenga algún valor; por el contrario hay peligro de sobrecarga de las funciones, sobre todo cuando se ponga en marcha el Examen Periódico Universal. Aun con el trabajo material que proporcionan todos los órganos de apoyo, órganos subsidiarios como el nuevo Comité Asesor, grupos de trabajo, relatores y expertos a su cargo, el Consejo tendrá dificultades para cumplir satisfactoriamente con su programa de trabajo.

En su primer período ordinario de sesiones, que empezó el 19 de junio de 2006 y terminó el 18 de junio de 2007, el Consejo sostuvo 5 sesiones ordinarias ${ }^{68}$

ves. Res. 1990/48 del ECOSOC, del 25 de mayo de 1990, en: E/1990/90, p. 37. Hasta el año 2000 tuvieron lugar períodos extraordinarios de sesiones para la exYugoslavia (agosto y octubre 1992), Rwanda (1994), Timor oriental (1999) y los territorios ocupados en Palestina (2000).

68 Primer período ordinario de sesiones (constitutivo) del 19 al 30 de junio de 2006, Segundo período ordinario de sesiones: del 18 de setiembre al 6 de octubre de 2006 y del 27 al 29 de noviembre de 2006; Tercer período ordinario de sesiones: del 29 de noviembre al 8 de diciembre de 2006, Cuarto período ordinario de sesiones: del 12 al 30 de marzo de 2007; Quinto período ordinario de sesiones: del 11 al 18 de junio de 2007. 
Ma. Cecilia AÑaños Meza • El Consejo de Derechos Humanos de Naciones Unidas...

y 4 sesiones especiales ${ }^{69}$ ocupándose de su organización y de temas fundamentales de derechos humanos tales como el derecho al desarrollo, el racismo, y otros.

Tras el término de su primer período de sesiones puede decirse que el balance es positivo puesto que en el plazo previsto sentó las bases de su institucionalidad. Ahora, en su segundo año, que se inicia en septiembre de 2007 no solo se verá si el Consejo está al día en su programa de trabajo sino también si lo cumple a satisfacción.

\section{EL ASPECTO FINANCIERO}

El factor financiero también influye en la eficacia de la función del Consejo. Los recortes del presupuesto traen consigo una limitación o reducción de los programas y proyectos que se quieran llevar a cabo. Asimismo, es un hecho conocido que los Estados influyen indirectamente aumentando o disminuyendo sus contribuciones.

69 Períodos extraordinarios de sesiones: Primer periodo extraordinario de sesiones: del 5 al 6 de julio de 2006, en el cual se condenó la operación militar de Israel en la Franja de Gaza; Segundo período extraordinario de sesiones: del 11 de agosto de 2006, en el cual se condenó la seria violación de los derechos humanos por Israel en Líbano; Tercer periodo extraordinario de sesiones: del 15 de noviembre de 2006, en el cual se examinaron las incursiones de Israel en los territorios ocupados de Palestina, y el Cuarto período extraordinario de sesiones: del 12 al 13 de diciembre de 2006, para tratar la situación en Darfur (Sudán).
En lo que se refiere a la financiación del Consejo, este se aseguró de contar con recursos para imprevistos, es decir, gastos no incluidos en el presupuesto de las Naciones Unidas durante el bienio 2006/200770. Para las Naciones Unidas, la creación del Consejo ha supuesto una suma adicional de 4,3 millones de dólares ${ }^{71}$.

A partir de 2008, su financiación se asegurará mediante los fondos provenientes del presupuesto general de las Naciones Unidas y contribuciones voluntarias. Como el Consejo es un órgano de la Asamblea General, a diferencia de la Comisión tiene la ventaja, de que sus propuestas y proyectos sean examinados por la Quinta Comisión y reciban mayor consideración de la Asamblea. Asimismo, en los últimos años ha aumentado el presupuesto para el área de derechos humanos, por lo que a corto plazo no se prevén serios recortes que puedan influir en la funcionalidad del Consejo.

\section{Posición del Consejo dentro del Sistema de DERECHOS HUMANOS DE LAS NACIONES UNIDAS}

El mejoramiento de la posición política del Consejo a raiz de su calidad de órgano de la Asamblea General

70 Véase el presupuesto por programas para el bienio 2006-2007: A/RES/60/247.

714.328 .700 dólares (cifras netas) estima la Quinta Comisión en su informe a la Asamblea General, véase A/60/721. 
confirma su status de órgano central en materia de derechos humanos dentro del sistema de las Naciones Unidas. Mas existen otros órganos del sistema que también se dedican a los derechos humanos ${ }^{72}$, con lo cual en muchos casos es difícil diferenciar o separar competencias dentro de la organización, lo que se traduce en duplicaciones innecesarias que al mismo tiempo implican sobrecargas en el presupuesto. Sin embargo, en las Naciones Unidas hay una relación importante entre el Consejo, el ECOSOC, la Oficina del Alto Comisionado para los Derechos Humanos y los diversos comités creados en virtud de los tratados sobre la materia.

Una cuestión abierta es el rol que desempeñará el ECOSOC en el futuro en materia de derechos humanos. Según el Art. 62 (2) de la Carta de las Naciones Unidas tiene el mandato específico de ocuparse de los asuntos de derechos humanos. Si bien el ECOSOC creó la Comisión cumpliendo el mandato de la Carta, en la práctica disminuyó su papel como órgano central para los derechos humanos mientras la Comisión crecía en importancia en este ámbito. De todos modos, los órganos subsidiarios del ECOSOC dedicados a los derechos humanos, como la Comisión sobre la

72 Entre otros: el Alto Comisionado para los Derechos Humanos, el ECOSOC, la propia Asamblea General y su Tercera Comisión y órganos especiales, los órganos creados por los Pactos Internacionales generales y especiales, el Alto Comisionado para los Refugiados, la UNESCO, y el UNICEF.
Condición Jurídica y Social de la Mujer, el Comité de Derechos Económicos, Sociales y Culturales y el Foro Permanente para las Cuestiones Indígenas deberán coordinar actividades y programas con el Consejo.

Por otro lado, en los últimos años la Oficina del Alto Comisionado para los Derechos Humanos, creada como resultado de la Declaración y Programa de Acción de Viena, ha crecido en importancia en el área de los derechos humanos. Su mandato, aún no claramente definido en la práctica, se extiende desde materias administrativas y preventivas, pasando por la promoción de los derechos humanos hasta los asuntos de racionalización y coordinación ${ }^{73}$. Su relación con el Consejo es de apoyo administrativo, material y presupuestario, así como de coordinación, convirtiéndose no solo en una «estación» de derechos humanos dentro del sistema de las Naciones Unidas sino adquiriendo un rol más activo al responder a situaciones de emergencia.

En cuanto a los siete Comités creados por tratados de derechos humanos, se hace necesaria una mejor coordinación e interacción entre ellos y el Consejo, tarea no muy fácil en la práctica, ya que estos órganos convencionales tienen vida independiente, son autónomos y se entienden como órganos técnicos dentro del sistema de derechos humanos de

73 Véase el parráfo 2 de la Res. 48/141 de la Asamblea General, de 20 de diciembre de 1993, (A/RES/48/141). 
Ma. Cecilia AÑaños Meza • El Consejo de Derechos Humanos de Naciones Unidas...

las Naciones Unidas. Actualmente, su cooperación con el Consejo es tenua o casi inexistente. Lo cierto es que ahora están llamados a cooperar con el Consejo proporcionándole información en lo concerniente al procedimiento de Examen Periódico Universal.

\section{Críticas al Consejo}

Debido a que recién se ha establecido la base legal del proceso constitutivo del Consejo y tiene por delante su aplicación en la práctica, es prematuro hacer una evaluación. Solo expondremos los puntos que son objeto de crítica y veremos si representan un obstáculo para el logro de sus fines y objetivos.

\section{Falta de credibilidad}

Las críticas de falta de credibilidad se refieren tanto a su composición como a sus actuaciones. En cuanto a la primera, se lo critica por tener entre sus miembros a Estados acusados de violar los derechos humanos ${ }^{74}$, en cuanto a las segundas, se sostiene que no actúa con suficiente rigor o por no actuar contra gobiernos que violan los derechos humanos, como en el caso de Sudán en 2006. Tales reparos también se hicieron a la Comisión y condujeron a su disolución.

La creación del Consejo en la forma definida en la resolución es una

74 Estados como Arabia Saudita, Argelia, Cuba, China, Rusia, Túnez. decisión de la comunidad internacional representada en la Asamblea General de las Naciones Unidas, dejando de lado las circunstancias en que fue creado. Si se apostó por una entidad política antes que técnica, y universal antes que regional, estaban de por medio su representatividad y su legitimidad global. Un Consejo de derechos humanos como «club de democracias occidentales y abiertas» es una idea extraña a fines y principios del derecho internacional tales como la igualdad soberana de los Estados y los valores generales de democracia y pluralidad.

A nivel global la credibilidad no tiene que ver con la calidad de los miembros ni con la perfección de las actuaciones, sobre todo tratándose de un ámbito complicado y delicado como los derechos humanos. En el caso del Consejo se trata de crear políticas de derechos humanos que sean aceptables para toda la comunidad internacional y de conseguir que todos los Estados respeten los derechos humanos en sus países mediante el diálogo con él, no sobre él. Además, hay que tener presente que en el caso de un órgano mundial eminentemente político como el Consejo, la credibilidad solo puede estar asegurada mientras estén representados en él todos los Estados del planeta y mientras haya un equilibrio de todas las fuerzas políticas globales. Una vez roto este equilibrio en favor de una u otra fuerza, se podrá hablar de riesgos o de falta de credibilidad. Las condiciones actuales de creación del Consejo le dan cierto equilibrio. 


\section{Politización}

El Consejo es visto por sus críticos también como un órgano politizado. Si bien politizar es «dar contenido político a acciones, pensamientos, etc., que corrientemente no lo tienen ${ }^{75}$, es fácil imaginar que a nivel internacional el asunto de los derechos humanos está necesariamente inmerso en posiciones e intereses políticos de todos los Estados miembros. El ambiente de confrontación en materias delicadas para uno de los miembros, la polarización o conflicto de intereses entre los Estados; la formación de bloques para asegurar posiciones; la negociación y búsqueda de consenso, serán la regla en la práctica del Consejo, como lo fue en los últimos años de la Comisión.

Inevitablemente la posición geopolítica y las relaciones políticas de los Estados entre sí se trasladan al Consejo. No es pues de sorprenderse que haya intentos de instrumentalizar los derechos humanos y que los Estados no estén libres de prejuicios políticos o dobles raseros. El bloque occidental se seguirá preocupando por mantener altos los estándares de derechos humanos y a la vez impedir o excluir a Estados que tengan problemas de derechos humanos y con los que tenga problemas diplomáticos y de seguridad; en cambio los Estados del bloque del Sur tendrán que defenderse de acusaciones y hacer

75 Diccionario de la Lengua Española, (1992) Madrid, Real Academia Española, XXI Ed. frente a las presiones y deberán pulir su imagen si desean mantener su asiento o ser reelegidos.

Por lo menos un equilibrio político está dado en el Consejo: los países occidentales compensarán su desventaja numérica con su sobrepeso económico y político, buscando alianzas o ejerciendo mayor presión como Estados financiadores de recursos y ayuda al desarrollo. Los países del Sur utilizarán su ventaja numérica para defenderse de acusaciones y presiones y abogar por sus propias políticas de derechos humanos, o para apuntar a situaciones de derechos humanos que disgustan a Occidente, esto en la medida en que lo permita su dependencia económica y política de los Estados occidentales.

A pesar de esta politización que, podríamos decir, es un «mal» inevitable, las decisiones del Consejo alcanzan un alto grado de profesionalidad y coherencia gracias a los órganos especializados y a los expertos a su cargo, y al menos en su primer año de vida sus actuaciones han sido productivassus.

\section{Selectividad al reaccionar a violaciones de los derechos bumanos}

Al Consejo se le critica también que actúa selectivamente frente a violaciones de los derechos humanos, en especial al tratar la situación de Palestina, Líbano y Sudán. Las críticas vienen sobre todo de intelectuales, políticos y medios de información occidentales. 
Ma. Cecilia AÑaños Meza • El Consejo de Derechos Humanos de Naciones Unidas...

En cuanto a los dos primeros casos, se señala que se ha reunido tres veces y solo ha condenado acciones de Israel ${ }^{76}$. En cuanto al tercero, se le observa que es tolerante con el gobierno de Sudán y ha reaccionado tardíamente y solo bajo presión.

Sin entrar a examinar las decisiones del Consejo en estos casos, se puede decir que cierto grado de selectividad es connatural al Consejo y tendrá que ser tolerado, salvo que la quiera eliminar completamente, lo que significaría tener que disolver el Consejo y crear un órgano diferente, independiente y profesional. El problema es que un órgano con estas características carecería de autoridad y necesitaría el apoyo de un órgano político que respalde su mandato.

Otro problema es que en las condiciones actuales, el Consejo no tiene la posibilidad material de responder a todas las emergencias de derechos humanos en el mundo. En la práctica solo puede responder a algunas. La pregunta es: ¿a cuáles sí y a cuáles no? ¿A las que alcanzan las páginas principales de los medios de información y captan la atención de los políticos? Indudablemente ello sería selectividad.

La selectividad solo puede reducirse adoptando criterios objetivos para responder con prontitud a situaciones de emergencia en derechos humanos y estableciendo bien las competencias de los órganos dentro del sistema de las Naciones Unidas. La forma, el momen-

76 Comp. críticas de Hampson (2007): 15. to y la necesidad de responder deben estar claras, tanto para el Consejo como para toda la comunidad internacional. Como adelanto se puede decir que el Consejo solo está obligado a actuar dentro de los límites de su mandato y en conexión con los mecanismos que tiene a su disposición y que descartan todo accionismo o automatismo.

\section{Problema de racionalización}

El traslapo de funciones en las Naciones Unidas, especialmente en el ámbito de los derechos humanos, es un problema serio que se agrava cuando hay cambios institucionales o se crean nuevos órganos por tratados internacionales o decisiones aprobadas en el seno de la Organización. El sistema de derechos humanos de esta se ha vuelto intransparente, complicado y enredoso, con multitud de normas, mecanismos y órganos que se interpolan arbitrariamente y confunden al mejor experto en la materia.

La práctica de las Naciones Unidas también revela que los cambios que apuntan a la racionalización no siempre la consiguen y terminan siendo un motivo más para una acción posterior con el mismo objetivo. Basta con señalar que no era necesario crear el Consejo puesto que ya existía un órgano de estructura similar.

El proceso de racionalización en materia de derechos humanos es apremiante y debe llevarse a cabo dentro y fuera del Consejo. En el primer caso se hace 
necesario perfeccionar los mecanismos que tiene a su disposición, y en el segundo será preciso coordinar la acción sobre todo con la Oficina del Alto Comisionado para los Derechos Humanos y ambos con los demás órganos internacionales de derechos humanos incluyendo los emanados del sistema convencional de las Naciones Unidas.

Pese a su inminencia y trascendencia para el desarrollo de los derechos humanos dentro de las Naciones Unidas, las críticas relativas a la falta de racionalización curiosamente no son tan vigorosas como las expuestas arriba. Este es en realidad un problema que debería ser objeto de la mayor atención no solo de los funcionarios de las Naciones Unidas sino de todos los grupos de presión y de la comunidad internacional en general.

\section{Falta de proporción entre las funciones y la institución}

Comparado con el que tenía la Comisión, el Consejo indudablemente tiene un mandato amplio y general en materia de derechos humanos. Mas existen temores fundados de que un órgano no permanente como el Consejo quede corto respecto de la magnitud de las funciones y tareas que se le han encomendado y traiga consecuencias negativas para la realización efectiva de sus funciones. Entre ellas está el no tratamiento de algunos asuntos o su tratamiento insuficiente o superficial, ámbitos que posiblemente no podrá cu- brir a cabalidad sin dotarse de órganos especializados adecuados relacionados con el derecho a la educación, el asesoramiento y la asistencia técnica y el Examen Periódico Universal.

\section{Conclusión}

No obstante estas críticas e incluso existiendo movimientos que han buscado desacreditar al Consejo desde su nacimiento ${ }^{77}$, se puede decir que su aspecto más fuerte es a la vez el más débil y está en su estructura universal y su carácter político.

La primera está asegurada siempre que en él estén representados los Estados de todas las regiones del mundo, aun tratándose de una estructura universal formal -en realidad no todos los Estados están representados, como en

77 El gobierno de Estados Unidos defiende la postura de un club de «Estados democráticos libres» defensores de derechos humanos aun fuera del sistema de las Naciones Unidas. Le siguen académicos como Ivo Daalder, James Lindsay, Ruth Wedgewood, Joshua Muravchik. Véase Joseph Loconte, «Relativism and Rights. Utopian illusions are preventing practical reforms of the Human Rights Commission", $\mathrm{Na}$ tional Review Online, accesible en:

$<$ http://www.nationalreview.com/comment/ loconte200602020832.asp> (visitado el 14 de agosto de 2007). Véase también Schaefer, Brett D. «The United Nations Human Rights Council: A Disastrous First Year and Discouraging Signs for Reform", The Heritage Foundation, accesible en: $<$ http://www.heritage.org/Research/InternationalOrganizations/tst072607a.cfm>, visitado el 25 de agosto de 2007. 
Ma. Cecilia AÑaños Meza • El Consejo de Derechos Humanos de Naciones Unidas...

el caso de la Asamblea General. Esta a su vez asegura la legitimidad de sus decisiones y actuaciones. El lado débil de su carácter universal es su falta de concreción en la creación de normas y en su actuación.

El carácter político tiene por consecuencia que sus decisiones y actuaciones estén investidas de autoridad y peso con consecuencias políticas de valor para los Estados, mas su lado débil está en los riesgos permanentes de politización y selectividad.

A la pregunta de si era preciso crear el Consejo sustituyendo a la Comisión puede contestarse negativamente debido a que no hay diferencias sustanciales entre ambos. Dejando de lado los cambios que ha traido consigo la creación del Consejo, la estructura y mandatos de ambas son idénticos. El proceso de reformas en pro del fortalecimiento del sistema de derechos humanos dentro de las Naciones Unidas habría podido realizarse con la Comisión. Ello nos lleva a concluir que la creación del Consejo no representa un avance significativo en el desarrollo institucional de los derechos humanos en las Naciones Unidas.

No obstante, su creación ha traído consigo algunas modificaciones de carácter institucional no carentes de importancia y en la práctica se verá si constituyen o no una mejoría en la promoción de los derechos humanos: un mejor posicionamiento político dentro de las Naciones Unidas, la existencia de estándares mínimos para los miembros del Consejo, el examen de todos los Estados miembros de la Organización para determinar sí cumplen con sus obligaciones de derechos humanos.

Lo expuesto tampoco debe menoscabar la importancia de la Comisión durante su existencia sirvió y actualmente del Consejo para el desarrollo de los derechos humanos a nivel global, mediante la aplicación de una política universal en la materia, velando por su cumplimiento, vigilando su aplicación por todos los Estados, actuando de foro universal y dotado de autoridad en la materia. La institución como tal es única en materia de derechos humanos, por tanto no puede reemplazarse ni compararse con otra a nivel regional o mundial.

Si el mayor logro de la Comisión fue la creación y desarrollo de un sistema normativo de derechos humanos basado en la Carta de las Naciones Unidas dotándole de fuerza jurídica y política mediante mecanismos de vigilancia y seguimiento, el reto del Consejo no solo consistirá en continuar el trabajo de la Comisión sino en sistematizar la normatividad internacional pertinente y en perfeccionar los mecanismos existentes a fin de lograr efectivamente y en plazos cortos un mejoramiento significativo y sustentable de la situación de derechos humanos en todos los Estados.

\section{BibLIOgRAFÍA}

Alston, Philip (1992), The Commission on Human Rights, en Alston, P. (ed.), The United Nations and Human Rights, Oxford, Clarendon Press, pp. 126-210.

Baum, Gerhart R. (2000), Die Menschenrechtskommission der Vereinten Nationen, 
Fastenrath (ed.), Internationaler Schutz der menschenrechte, Dresden, Dresden University Press, p. 78

Buergenthal, Thomas (1995): International Human Rights. In a Nutshell, (2 ed.), St. Paul, Min. West Publishing Co., p. 79 ss. Eide, Asbjørn (1992), The Subcommission on Prevention of Discrimination and Protection of Minorities, en Alston, P. (Ed.), The United Nations and Human Rights, Oxford, Clarendon Press, pp. 211-264.

Hampson, Françoise (2007), An Overview of the Reform of the UN Human Rights Machinery, Human Rights Law Review No.7:1, p. 7-27, p. 8.

Irmscher, Tobias H. (2002), Die Behandlung privater Beschwerden über systematische und grobe Menschenrechtsverletzungen in der UN-Menschenrechtskommission, Frankfurt am Main, Lang.

Nowak, Manfred (2006), De la Comisión de Derechos Humanos al nuevo Consejo, en Almqvist, J. y F. Gómez Isa, (eds.), El Consejo de Derechos Humanos: Oportunidades y Desafíos, Fride, sitio web: <http:// www.fride.org/Publications/Publication. aspx?Item $=1185>$.

Theissen, Gunnar (2006), Mehr als nur ein Namenswechsel. Der neue Menschenrechtsrat der Vereinten Nationen, Vereinte Nationen No. 4, pp. 138-146.

Villán Durán, Carlos (1996), Curso de derecho internacional de los derechos huma- nos, 27ème session d'enseignement, 1-26 juillet, Institut International des Droits de l'Homme, Estrasburgo, p. 337 ss.

Villán Durán, Carlos (2006), Luces y sombras del nuevo Consejo de derechos humanos de las Naciones Unidas, Eikasia. Revista de Filosofía 4 (mayo), sitio web: http:// revistadefilosofia.com/DH06.pdf.

Watson, C. y otros (2004), Fostering Constructive Dialogue: Building Toward More Effective Communication in the Educational Technology Field, Educational Technology, marzo-abril, pp. 54-58.

$<$ http://www.ci.hs.iastate.edu/prspstud/grad/ Grad2/facultypages/Watson \%20et \% 20 al..pdf>, visit. 10.08.2007.

Loconte, Joseph (2006), Relativism and Rights. Utopian illusions are preventing practical reforms of the Human Rights Commission, National Review Online, 2 de febrero de 2006, accesible en: <http:// www.nationalreview.com/comment/ loconte200602020832.asp>, (visitado el 14 de agosto de 2007).

Schaefer, Brett D. (2007), The United Nations Human Rights Council: A Disastrous First Year and Discouraging Signs for Reform, The Heritage Foundation, 26 de julio de 2007, accesible en:

<http://www.heritage.org/Research/InternationalOrganizations/tst072607a.cfm>, visitado el 25 de agosto de 2007. 